\title{
Absolutism, Relativism and Metaepistemology
}

\section{J. Adam Carter ${ }^{1}$ (D) $\cdot$ Robin McKenna $^{2}$ (D)}

Received: 14 September 2017 / Accepted: 1 July 2019 / Published online: 9 August 2019

(c) The Author(s) 2019

\begin{abstract}
This paper is about two topics: metaepistemological absolutism and the epistemic principles governing perceptual warrant. Our aim is to highlight - by taking the debate between dogmatists and conservativists about perceptual warrant as a case study — a surprising and hitherto unnoticed problem with metaepistemological absolutism, at least as it has been influentially defended by Paul Boghossian (Fear of knowledge: against relativism and constructivism, Oxford University Press, Oxford, 2006a) as the principal metaepistemological contrast point to relativism. What we find is that the metaepistemological commitments at play on both sides of this dogmatism/conservativism debate do not line up with epistemic relativism nor do they line up with absolutism, at least as Boghossian articulates this position. What this case study reveals is the need in metaepistemological option space for the recognition of a weaker and less tendentious form of absolutism, what we call "environment relativism". On this view, epistemic principles are knowable, objective, and they can serve as the basis of particular epistemic evaluations, but their validity is relative to the wider global environment in which they are applied.
\end{abstract}

\section{Introduction}

Paul Boghossian's (2006a) monograph Fear of Knowledge has set the agenda for philosophical discussions of relativism in epistemology over the past decade. At least in summary form, the metaepistemological picture Boghossian paints is simple. There are two salient, even if not exhaustive, metaepistemological options, which we will call "B-relativism" and "B-absolutism". ${ }^{1}$ The B-relativist is the villain of the

1 "B" because both views are formulated by Boghossian, in ways that some relativists and absolutists might not agree with. Note that while Boghossian briefly canvasses a metaepistemological position analogous to metaethical expressivism, this view isn't treated as a serious option. On the picture he offers-

J. Adam Carter

adam.carter@glasgow.ac.uk

Robin McKenna

rbnmckenna@gmail.com

1 University of Glasgow, Glasgow, UK

2 University of Liverpool, Liverpool, UK 
piece, a part often played by Richard Rorty. The B-relativist's motto is that "there are many radically different, yet 'equally valid' ways of knowing the world, with science being just one of them" (2006a, 2). In a little more detail, the B-relativist holds that particular epistemic judgements like "Galileo was justified in believing that the Earth revolves around the Sun" are only true or false relative to epistemic systems, where epistemic systems consist in sets of epistemic principles that state what kinds of things justify what kinds of doxastic states. As Boghossian sees it, the hero, the B-absolutist, wins the day against the B-relativist because the B-relativist is unable to provide a coherent account of epistemic justification. ${ }^{2}$ Choosing between what Boghossian sees as a commonsensical view like B-absolutism and a view that can't even be coherently stated isn't difficult.

Critical response to Boghossian's attack on B-relativism has principally focused-perhaps unsurprisingly — on whether B-relativism is in fact coherent. On this score, a point of particular interest for critics has been whether the B-relativist (or closely-related versions of relativism) can evade Boghossian's criticisms. ${ }^{3} \mathrm{We}$ submit, however, that both Boghossian's attack on B-relativism and the critical response to it have contributed to a kind of metaepistemological misdirection. There has been little discussion of whether B-absolutism is really as commonsensical and consonant with epistemological orthodoxy as Boghossian supposes, or of whether B-absolutism and B-relativism are the two most salient options. ${ }^{4}$

Both issues would be easier to resolve if metaepistemology were in as advanced a state as metaethics. Metaethical commitments are often explicitly articulated and well-studied. However, in metaepistemology, things are murkier. Mainstream epistemologists don't often articulate and evaluate metaepistemological commitments, but at most tacitly reveal them in the course of pursuing first-order projects. This makes the matter of assessing the accuracy of Boghossian's characterisation of the metaepistemological landscape-and his envisioned absolutist's place within this landscape — all the more difficult.

We think we can make progress on this issue by looking at some first-order epistemological debates, and trying to identify what metaepistemological commitments underpin these debates. The guiding idea is that we can identify metaepistemological commitments by looking at the pragmatic presuppositions (in the sense of Stalnaker 1974) of first-order epistemological debates (see Carter 2016, Ch. 1). Our aim will be to show that there are paradigmatic first-order epistemological debates

\footnotetext{
Footnote 1 (continued)

and as will be important in what we engage with here-the principal dispute features epistemic relativism on the one hand and (what we take to be a rather strict version of) metaepistemological absolutism on the other.

2 As Boghossian puts it, there is ultimately "no way of construing the notion of an epistemic system so as to render stable a relativistic conception of epistemic justification" (2006a, 92-93).

3 See, for example, Carter (2016), Kusch (2010), MacFarlane (2008, 2014), Neta (2007), Rosen (2007), Sosa (2008), Wright (2008). Cf. Boghossian (2007, 2008).

4 This is important given that Boghossian's argument for B-absolutism goes like this: “[...] there are decisive objections to epistemic relativism. It would seem, then, that we have no option but to think that there are absolute, practice-independent facts about what beliefs it would be most reasonable to have under fixed evidential conditions" (2006a, 110). Clearly, this relies on B-absolutism being the only alternative to B-relativism.
} 
whose metaepistemological commitments (on both sides) line up with neither B-relativism nor B-absolutism. In particular, we will use as a case study the recent debate about perceptual warrant between dogmatists (e.g. Pryor 2000, 2004) and conservativists (e.g. Wright 2004, 2007; Davies 2000). As we will argue, while both views clearly reject B-relativism, they are also in tension with some of the core tenets of B-absolutism. ${ }^{5}$

Accordingly, we will conclude that Boghossian's characterisation of the metaepistemological landscape is, indeed, misleading: there are some views that are live options, but should not be understood as committed to either B-absolutism or B-relativism. Note that it is no part of our argument that these epistemological views are correct (they may well not be), or that they exhaust the space of epistemological options (they clearly don't). But, if these views are false, we submit it is because they are false as first-order epistemological views, not because of their metaepistemological commitments. As we will see, saddling them with a commitment to B-absolutism or B-relativism would lead to serious problems, so there is good reason not to take their proponents to be committed to B-absolutism or B-relativism.

This leaves open the question of what sort of metaepistemological picture they should be combined with. We propose that it would be profitable to see these views as committed to a weaker form of absolutism we term environment relativism ("E-relativism"). That is, they should hold, in conjunction with other absolutist tenets, that there is not a uniquely correct set of epistemic principles that apply to all rational agents in all places at all times. Rather, there are different epistemic principles for different rational agents. The validity of a set of epistemic principles is relative to the wider global environment in which they are applied. Note that it is also no part of our argument that what we are calling E-relativism is true. Rather, our claim is that we have erred in following Boghossian and taking B-absolutism and B-relativism to exhaust the space of metaepistemological options.

Here is the plan. Section 2 articulates the key components of B-absolutism. Section 3 contains our first case-study: the debate between dogmatists and conservativists. We argue that neither view should be read as committed to B-absolutism or B-relativism. Section 4 closes by refining the kind of absolutist-tinged E-relativism we propose as a "third way" between B-absolutism and B-relativism.

\section{B-Absolutism}

B-absolutism is a form of metaepistemological realism. Metaepistemological realism is (roughly) analogous to metaethical realism, in that the metaepistemological realist is committed to mind-independent epistemic facts-e.g. facts about what

\footnotetext{
5 To be clear, we are not attempting to suggest, through this case study, that many and especially not all first-order epistemological debates presuppose metaepistemological commitments at odds with B-absolutism. More modestly_our dialectical aim just requires showing that there are some views that (a) are "live options" in epistemology yet (b) don't presuppose B-absolutism or B-relativism. If we can do this, we will have shown that Boghossian's characterisation of the metaepistemological landscape is misleading.
} 
beliefs are justified by what evidence, which beliefs count as known, etc. ${ }^{6}$ B-absolutism goes beyond minimal metaepistemological realism, though Boghossian does not define B-absolutism all in one place. In order to get the position clearly in view, we'll need to cobble together the key aspects of his view, as expressed over several chapters in Fear of Knowledge and in other work (e.g. Boghossian 2001, 2006b).

As we'll see, Boghossian's metaepistemological absolutism consists in five core theses, centred on epistemic principles. Here some terminological clarity is needed. Boghossian distinguishes between an epistemic rule and an epistemic principle. Rules take the form: if conditions $C$ obtain, believe $X$. For example: "If lighting conditions are good, etc., and it visually seems to you as if there is a cat in front of you, then believe that there is a cat in front of you" (Boghossian 2001, 2). The claim that different cultures employ different rules is descriptive; for example, the Azande have a rule of the form: if the Poison Oracle indicates that $X$, believe $X$. Western cultures do not follow this rule. By following epistemic rules, we implicitly commit ourselves to epistemic principles. For example, a culture that follows the Poison Oracle rule is implicitly committed to a more general epistemic principle to the effect that Poison Oracle-based beliefs are justified. So, as Boghossian defines them, epistemic principles are "general normative propositions" which specify conditions under which a particular type of belief is justified (Boghossian 2006a, 85, 2001, 38 fn. 3).

Just as we might follow different rules to the Azande when engaging in inquiry, we might believe that different epistemic principles are true. But what happens when we disagree about which epistemic principles are true? This turns on a deeper question: what is the status of epistemic principles? Boghossian says this:

[T] he thesis of the objectivity of reasons can be stated as the claim that there is an objective fact of the matter which epistemic principles are true, and, consequently, which sets of rules a thinker ought to employ to shape his beliefs, if he is to arrive at beliefs that are genuinely justified $(2001,2)$.

The thought is that there are objective facts about which epistemic principles are true, and so there is a uniquely correct set of principles that a rational agent ought to employ (namely, the principles that are objectively true). So Boghossian endorses OBJECTIVITY and UNIVERSALITY:

OBJECTIVITY: There is an objective fact of the matter which epistemic principles are true.

UNIVERSALITY: There is a uniquely correct set of epistemic principles, which all rational agents are bound by.

OBJECTIVITY and UNIVERSALITY raise some interesting questions in metaepistemology. How do we get at these objective facts? Through standard epistemological methodology? In what sense are they "objective"? In particular, are they objective in the sense that they are independent of the cognitive makeup of humans?

\footnotetext{
${ }^{6}$ For the most sustained recent discussion of metaepistemological realism, understood as an analogue to metaethical realism, see Cuneo (2007, chap. 3). Opponents of realism include error-theorists like Olson (2011) and Streumer (2013) and expressivists like Chrisman (2007), Field (2009) and Gibbard (1990).
} 
What about non-human epistemic agents, or agents situated in very different environments? Why should principles that are true for us be true for them? We set these questions aside for now, but we return to them below.

Boghossian also addresses the question of the relationship between epistemic principles and particular epistemic evaluations:

Now, an epistemic system, we have said, consists of a set of general normative propositions_epistemic principles_-which specify under which conditions a particular type of belief is justified. Whereas a particular epistemic judgment might speak of particular people, beliefs and evidential conditions, as in:

3. If it visually seems to Galileo that there are mountains on the moon, then Galileo is justified in believing that there are mountains on the moon;

an epistemic principle will say something general like:

(Observation) For any observational proposition $\mathrm{p}$, if it visually seems to $\mathrm{S}$ that $\mathrm{p}$ and circumstantial conditions $\mathrm{D}$ obtain, then $\mathrm{S}$ is prima facie justified in believing $\mathrm{p}$. In other words, and as we can plainly see, the epistemic principles which constitute particular epistemic systems are just more general versions of particular epistemic judgments (2006a, 86).

The thought is that particular epistemic evaluations ("Galileo is justified") are explainable by reference to more general epistemic principles (like Observation). Now, if particular epistemic evaluations are to be explainable by reference to more general epistemic principles, there must be some sort of connection between them. Boghossian suggests that the relationship between particular evaluations and the more general principles is like the relationship between "Socrates is mortal" and "all men are mortal" (2006a, 87). That is, it is a form of entailment. So Boghossian endorses GENERALISM and ENTAILMENT:

GENERALISM: Particular epistemic evaluations are explainable with reference to epistemic principles.

ENTAILMENT: Entailment relations hold between epistemic principles and particular epistemic judgments.

Boghossian is a "generalist" in the sense that he denies the sort of particularism defended in Dancy (2004). The bone of contention between the generalist and the particularist is over whether there are any properties of beliefs and belief-forming processes (e.g. being reliably produced, being based on good evidence) that make the same "epistemic difference" in all cases. The generalist holds that there are; the particularist holds that there aren't. On the generalist's view, particular epistemic evaluations are grounded in principles that state which properties make beliefs justified, and more generally are necessary and/or sufficient for the possession of certain kinds of epistemic statuses. So any epistemological project that attempts to specify necessary and/or sufficient conditions for the possession of certain kinds of epistemic statuses and then uses these conditions as the basis for particular epistemic evaluations accepts GENERALISM. 
One might worry about the idea that particular epistemic evaluations are grounded in epistemic principles. But it is important to distinguish between a strong deontological and a theoretical conception of the epistemic principles used in epistemological theorizing. According to the strong deontological conception of epistemic principles, what grounds positive epistemic status is accordance with epistemic principles which themselves forbid or permit certain kinds of beliefs. As William Alston puts it:

To say that $\mathrm{S}$ is justified in believing that $p$ at time $\mathrm{t}$ is to say that the relevant rules or principles do not forbid S's believing that $p$ at $\mathrm{t}$. In believing that $p$ at $\mathrm{t}, \mathrm{S}$ is not in contravention of any relevant requirements $(1988,258)$.

On this conception, epistemic evaluations depend on epistemic principles in a strong metaphysical sense: epistemic status is status in virtue of according with epistemic principles; alternatively, the fact of some belief's being justified, known, etc., obtains because the fact of that belief's according with some epistemic principle (or principles) obtains. The relationship between epistemic status and epistemic principles here is thus one of grounding. ${ }^{7}$ Grounding implies necessitation in the sense that, if $p$ grounds $q$, then necessarily, if $p$ is true then $q$ is true (see, for example, Fine 2012; Sider 2015). So if, as the strong deontological conception has it, according with epistemic principles grounds epistemic status, then it follows that epistemic status depends on epistemic principles. But, the relationship between grounding and necessitation is one of asymmetric entailment. Necessitation does not entail grounding. An example that Theodore Sider (2015) offers on this point concerns the claim that the non-moral necessitates the moral. This is, as Sider notes, a claim that is accepted by moral naturalists and non-naturalists alike. The difference is that moral naturalists think that moral facts obtain in virtue of non-moral facts, whereas moral non-naturalists deny that moral facts obtain in virtue of non-moral facts.

This difference is important because it means that one can insist that epistemic principles necessitate epistemic status without committing to the strong deontological view that epistemic status just is a matter of according with epistemic principles. Foundationalists (such as Chisholm) and some epistemic internalists (e.g. Ginet (1975)) view justification and knowledge as dependent on epistemic principles in the strong deontological sense. However, reliabilists, along with most other epistemologists, think that epistemic principles necessitate epistemic status, but deny the strong deontological view. We'll call this the theoretical conception of the epistemic principles used in epistemological theorizing. GENERALISM can be understood in two ways, corresponding to the two different conceptions. If one is unhappy with the idea of particular epistemic judgements being grounded in more general epistemic principles, one should opt for the theoretical over the strong deontological conception.

The final piece of Boghossian's absolutist package has to do with our access to epistemic principles:

Whenever we confidently judge that some belief is justified on the basis of a given piece of information, we are tacitly assuming that such facts are not only knowable but that they are known. And in doing epistemology, we not only

\footnotetext{
7 For a contemporary overview of this topic, see Correia and Schneider (2012).
} 
assume that they are knowable, we assume that they are knowable a priori. Indeed, what would be the interest of an absolutism about epistemic truths which combined that absolutism with the affirmation that those truths are necessarily inaccessible to us? (Compare: what would be the interest of an absolutism about moral truths which combined it with the affirmation that those absolute truths are necessarily inaccessible to us? (2006a, 77; our italics).

The thought is that any interesting form of absolutism must hold that it is possible to form justified beliefs about the uniquely correct set of epistemic principles. So Boghossian endorses KNOWABILITY:

KNOWABILITY: If there are objective facts about which epistemic principles (and which particular epistemic judgements) are true, these facts should be knowable: it ought to be possible to arrive at justified beliefs about them ${ }^{8}$

Putting the pieces together, B-absolutism consists in five claims:

OBJECTIVITY: There is an objective fact of the matter which epistemic principles are true

UNIVERSALITY: There is a uniquely correct set of epistemic principles, which all rational agents are bound by.

GENERALISM: Particular epistemic evaluations are explainable with reference to epistemic principles.

ENTAILMENT: Entailment relations hold between epistemic principles and particular epistemic judgments.

KNOWABILITY: If there are objective facts about which epistemic principles (and which particular epistemic judgements) are true, these facts should be knowable: it ought to be possible to arrive at justified beliefs about them.

We get a picture on which, when we make particular epistemic judgments, we can explain these by pointing to an objectively true and uniquely correct set of general epistemic principles from which these judgments follow, where both the principles and the judgments that follow from them are knowable, and the principles govern every rational agent.

\section{Case Study: Epistemology of Perception}

If Boghossian is right that B-absolutism is consonant with commonsensical and traditional thinking (and that B-relativism isn't), then we should expect that core principles of B-absolutism identified above are among-or, at the very least not at tension with - the metaepistemological presuppositions that feature in the common

\footnotetext{
${ }^{8}$ Boghossian adds that, in the case of complicated epistemic principles, it's not necessary that we know them in 'their full detail' (2006a, 75-76).
} 
ground of typical first-order epistemological debates. In this section we look at one such debate-one concerning our epistemic warrant for perceptually formed beliefs - and argue that the principal views we consider are best read as rejecting at least one of the five core tenets of B-absolutism.

As noted at the outset, we do not assume that the views we consider in this case study, dogmatisim and conservativism, are correct. (Indeed, they could not both be correct, given they are inconsistent!) We also don't assume that they exhaust the space of options. They certainly don't (see e.g. Lyons 2009; Siegel 2010). Indeed, the dogmatism/conservativism dispute is but one representative in-house dispute in the epistemology of perceptual warrant, one where (we shall show) neither side is committed to all the tenets of B-absolutism. And this is itself enough to make serious mischief for the suggestion that the B-absolutist package (replete with its five constituent components) is the only viable alternative to B-relativism.

\subsection{Dogmatism and Conservativism}

The point of contention in the debate between dogmatists and conservativists concerns whether our perceptual experiences give us immediate (viz., non-inferential, and not presupposing any other beliefs) prima facie justification for believing their contents. Dogmatists like Jim Pryor answer in the affirmative (see Pryor 2000, 2004). As Pryor puts it:

The dogmatist about perceptual justification says that when it perceptually seems to you as if $p$ is the case, you have a kind of justification for believing $p$ that does not presuppose or rest on your justification for anything else [...] To have this justification for believing $p$, you need only have an experience that represents $p$ as being the case. No further awareness or reflection or background beliefs are required. Of course, other beliefs you have might defeat or undermine this justification. But no other beliefs are required for it to be in place $(2000,519)$.

Dogmatism entails that, if one has an experience as if $p$, then one is thereby prima facie justified in believing that $p .{ }^{9}$ Of course, the dogmatist's prima facie clause means that the justification in question is defeasible. For example, if one has an experience of a wall being red, but one mistakenly believes one is wearing red-tinted glasses, then one's prima facie justification is defeated. ${ }^{10}$ Nonetheless, according to the dogmatist, even if the epistemic significance of perceptual experience can in

\footnotetext{
9 Note that Pryor's dogmatist is "not saying that your justification for believing $p$ rests on your awareness of your experiences. His view is that you have justification for believing $p$ simply in virtue of having an experience as of $p$ " (2000, 519-20). Granted, the dogmatist allows that you can of course become aware of your experiences through introspection. Further, Pryor's dogmatist allows that one can attain justification for believing $p$ that rests on introspective awareness and background beliefs. The crucial point of dogmatism is just that, as Pryor stresses, "there is a kind of justification you have which does not rest on these things" (ibid.).

10 This would be an instance of what is called, in the defeasibility literature, an undercutting mental-state (or psychological) defeater. For discussion, see Pollock (1986) and Sudduth (2008).
} 
some cases be overridden, perceptual experience as such is in all cases epistemically significant. We can thus state the core thesis of dogmatism as follows:

DOGMATISM: Our experiences, as such, give us immediate and prima facie justification for believing their contents. ${ }^{11}$

Conservativists reject the dogmatist's claim that our experiences give us immediate and prima facie justification for believing their contents. This is the conservativist's negative thesis:

CONSERVATIVISM-NEGATIVE: It is not the case that our experiences, as such, give us immediate prima facie justification for believing their contents.

The conservativist pairs this negative claim with a statement specifying what extra information is needed in order for experiences to give prima facie justification for believing their contents. Call this the conservativist's positive thesis:

CONSERVATIVISM-POSITIVE: In order for experiences to give us prima facie justification for believing their contents, extra information is needed; their simply being experiences as if such-and-so is not sufficient; what is needed, additionally, is (i) that there is an external world with which one is causally interacting; and (ii) that the external world is mostly correctly revealed to one through sense experience. $^{12}$

Of course, if conditions (i) and (ii) were hard to meet, scepticism would threaten. However, on Wright's conservativist line, satisfying these conditions is easy. We have "unearned rational warrants", what Wright calls entitlements, to (i) and (ii). ${ }^{13}$ Thus:

CONSERVATIVISM-ENTITLEMENT: We have entitlements (i.e., unearned rational warrants) to (i) and (ii).

Putting these pieces together, the conservativist is committed to this thesis:

CONSERVATIVISM: Our experiences give us prima facie justification for believing their contents, not simply because they are experiences as if such-and-so, but because we are entitled in accepting that there is an external world with which

\footnotetext{
11 Similarly liberal principles are found elsewhere in epistemology albeit with different caveats and provisos. Notable examples of liberal epistemic principles include Burge's (1993) acceptance principle (which we return to below) and Huemer's (2007) principle of phenomenal conservativism.

12 This characterization of the view is based on Coliva (2012), who expresses the position she thinks Wright (2004) and Davies (2000) both defend.

13 Wright says, of entitlement: "Suppose there is a type of rational warrant which one does not have to do any specific evidential work to earn: better, a type of rational warrant whose possession does not require the existence of evidence in the broadest sense encompassing both a priori and empirical considerations for the truth of the warranted proposition. Call it entitlement. If I am entitled to accept P, then my doing so is beyond rational reproach even though I can point to no cognitive accomplishment in my life, whether empirical or a priori, inferential or non-inferential, whose upshot could reasonably be contended to be that I had come to know that P, or had succeeded in getting evidence justifying P" (2004, 174-75).
} 
one causally interacts and that this world is mostly correctly revealed through sense experience.

The story Wright tells about why we have these entitlements, and about their nature, is sophisticated, and we need not explore it in depth here for our purposes. It suffices to focus on what (rather than why) the dogmatist and the conservativist are saying as, in each case, we find general statements of conditions under which a particular kind of belief - in this case, perceptual beliefs - have a positive epistemic status. That is, the dogmatist and the conservativist are committed to particular epistemic principles (DOGMATISM and CONSERVATIVISM).

This completes our overview of the debate between dogmatists and conservativists. In Sects. 3.2-4 we argue that both of the principles about perceptual justification identified above (DOGMATISM and CONSERVATIVISM) require rejecting one of the core tenets of B-absolutism. To re-iterate: the point is not that one of these views about perceptual justification is correct (they can't both be correct!), or that they exhaust the space of options. Rather, the point is that these are live options in the epistemology of perception, and, as we will argue, it would be a mistake to see them as being committed to the full B-absolutist package.

\subsection{Dogmatism and Universality}

B-absolutism holds that epistemic principles satisfy OBJECTIVITY and UNIVERSALITY. That is, any true epistemic principle is a member of a unique set of objectively true principles that all rational agents are bound by. Let's assume, ex hypothesi, that DoGMATISM $i$ s correct and so in fact is within this set. We're particularly interested in UNIVERSALITY. UNIVERSALITY implies that, if DOGMATISM is true for us, then it is also true for individuals who find themselves in very different, perhaps extremely different, circumstances than we do; their experiences, no less than ours, furnish such individuals with immediate prima facie justification for believing their contents. We are going to argue that this is implausible.

One kind of circumstance which is very different from our ordinary circumstances (at least, very different as regards the connection between our experiences and our beliefs about their contents), are houses of illusions, intentionally designed to make things appear differently than as they are. But the existence of such local environments, located as they are within our more epistemically hospitable global environment, causes no problem for the conjunction of DOGMATISM and UNIVERSALITY. If one is (unwittingly) in a house of illusions, one still has immediate prima facie justification for believing the contents of one's illusory experiences. It's just that this prima facie justification is very easily defeated; for instance, if one finds out one is in a house of illusions. ${ }^{14}$ This seems like the right result, at least, from within the tradition of epistemology according to which epistemic justification needn't be

\footnotetext{
14 This might happen, for instance, either directly by testimony, or indirectly, as one begins to acquire track record evidence that perception is unreliable in this local environment.
} 
truth-entailing. ${ }^{15}$ Given that our sense experience does generally reveal our world as it actually is - that is, houses of illusions, strange lightning, deceptive designs, hallucinations, and the like-are the exception, not the norm, it is at least somewhat plausible that our world is one where justification functions as the dogmatist says. It is plausible that we have prima facie justification for our perceptual beliefs precisely because our world is mostly correctly revealed to us. This is compatible with the fact that, when one acquires some reason to believe one's perceptual experiences are illusory, one lacks ultima facie justification for believing the contents of one's illusory experiences.

But, remember that UNIVERSALITY entails that if DOGMATISM is true for us, then it is true as well for individuals who find themselves in very different, perhaps even radically different, circumstances. We are fortunate in that our world is mostly correctly revealed to us. It is plausible that our perceptual systems reliably represent our environment because doing so contributed to our survival. As the vision scientist Stephen Palmer puts it:

vision evolved to aid in the survival and successful reproduction of organisms. Desirable objects and situations b.\# $\psi$ must be sought out and approached. Dangerous objects and situations [...] $\psi$ must be avoided or fled from. Thus, to behave in an evolutionarily adaptive manner, we must somehow get information about what objects are present in the world around us, where they are located, and what opportunities they afford us (Palmer 1999, 6).

But this is a contingent fact about the kind of creatures we are, and the sort of world we happen to inhabit. While our perceptual faculties produce beliefs that, in normal conditions, are largely true, we can imagine creatures who are not so lucky. That is, we can certainly imagine creatures for whom reliably representing the environment did not contribute to their survival. Take rabbits. ${ }^{16}$ Rabbits have perceptual systems for detecting danger, but these systems produce a large number of false-positives. They generally correctly identify dangerous things as dangerous, but they regularly incorrectly identify safe things as dangerous. We can tell a story where this was vital to the survival of rabbits; it is far better for rabbits to be safe than to be sorry, so there is an evolutionary rationale for having systems for detecting danger that systematically produce false beliefs (cf. Stich 1991).

With a little imagination, we can imagine creatures with perceptual systems that not only systematically get things wrong about what is dangerous, but systematically produce a large number of false beliefs about their external environment. Perhaps it is more important that our creatures have beliefs that make them happy than it is that they have beliefs that are true (if they don't have beliefs that make them happy, they experience crippling depression). Or perhaps their environment is such that it would be more trouble than it is worth for them to accurately represent their external

\footnotetext{
15 Epistemological disjunctivism (e.g. McDowell 1994; Pritchard 2012) challenges this But this is a contingent fact about the kind of creatures we are, and the sort of world we happen to inhabit. While our perceptual faculties produce beliefs that, in normal conditions, are largely true, we can imagine creatures who are not so lucky. tradition.

16 We take this example from Graham (2012).
} 
environment. Imagine they live in a world of plenty, where they have abundant food, no problem finding mates, no predators, and no competitors. In such an environment, you don't need true beliefs about where the food is or where a likely mate is; food and likely mates are everywhere. You don't need sophisticated systems for identifying threats because there are no threats. Because these things aren't needed, there would be no reason for our creatures to have them.

We want to pause to emphasise two things about the sorts of scenarios we are envisaging. First, even those who think that the evolutionary origins of our perceptual systems is an essential part of an epistemological account of our justification for our perceptual beliefs grant that it is a contingent fact that our perceptual systems were "selected for" because they reliably produced true beliefs. The point is not that evolution had to provide us with reliable perceptual systems; the point is that it did, and we can view this as relevant to perceptual justification. Here is how Peter Graham (a prominent advocate of this sort of view) puts it:

[I]t is not a priori necessary that every creature with its environment [sic.] by employing reliable representational systems. But we knew that already. What is at issue is whether some cognitive systems as a matter of fact were replicated because they reliably produced true beliefs. I am not arguing that natural selection would select for reliability; I am only arguing that it did. Though Mother Nature doesn't pursue truth for-its-own sake, sometimes pursuing truth for the sake of survival is her best option (Graham 2012, 475; emphasis in original).

So there is nothing inconceivable about creatures whose perceptual systems were replicated not because they reliably produced true beliefs, but for some other reason.

Second, perhaps there are compelling reasons for thinking that our perceptual systems could not, as a matter of necessity, produce beliefs that are uniformly false. Some will want to defend this with reference to the Davidsonian idea that belief is by nature veridical (see e.g. Davidson 1986). Others will cite the Quinean idea that falsehood is not conducive to survival (Quine 1969). While this is a complex issue, we are relying on what we take to be an important, if under-appreciated, point. We can grant that there is a degree or level of error such that, if a perceptual system (or belief-producing system in general) falls below it, interpretation is impossible (Davidson) or survival is very unlikely (Quine). Call this level the 'Quinean threshold'. But there is no obvious reason why the Quinean threshold needs to be particularly high. More importantly, there is no obvious reason why it needs to be even close to the level that would be required for perception (or some other system) to be reliable. ${ }^{17}$ To see this point, consider the rabbits. It may be that their systems for detecting danger need to get it right enough to survive. Indeed, this is very plausible;

\footnotetext{
17 One might be inclined to suggest at this juncture a kind of constitutive line against supposing that our perceptual systems could ever be unreliable in general, and still count as perceptual systems, as opposed to, say, some other kind of system. Such a line might gain some intuitive plausibility from the suggestion that perception is a kind of 'success term' in some sense that would render incoherent the thought that perception could be unreliable en masse. But perception is not a success term, any more than belief is a success term. There is no reason to suppose that in a world where the practice of believing was unreliable
} 
if these systems didn't identify dangerous things as dangerous, then rabbits would not survive, or at least not for very long. But this is no reason to suppose that their systems for detecting danger are reliable. Reliable enough for survival doesn't mean reliable. It just means that they get things right enough for rabbits to reproduce. ${ }^{18}$

For these reasons, we don't take the sorts of creatures and scenarios we are envisaging to run into any obvious problems with Davidsonian ideas about interpretation, ${ }^{19}$ or the less philosophically-loaded idea that creatures need true beliefs in order to survive. The point is just that one can have enough true beliefs to be interpretable or to survive while still having more false than true beliefs.

What can we say about our creatures from the perspective of DOGMATISM? Let's assume, ex hypothesi, that DOGMATISM is correct. If we combine DOGMATISM with UNIVERSALITY, we get the result that the experiences of our creatures furnish them with immediate prima facie justification for believing their contents, in exactly the same way as our experiences furnish us with such justification. But this seems straightforwardly false. Consider the difference between our creatures and someone who is unwittingly in a house of illusions. When one is in unwittingly a house of illusions, one might still have prima facie immediate justification because the house is itself situated within a wider global environment that is mostly correctly revealed to one through perception. But our creatures are situated within a wider global environment that is not mostly correctly revealed to them through perception. Once you strip away the friendly wider global environment, you strip away the rationale for supposing there is prima facie immediate justification.

Before turning to conservativism, we would like to raise and respond to an objection. Although the crux of Pryor's dogmatism is the claim that our experiences give us the immediate justification they do, in places Pryor goes further and says what it is about our experiences in virtue of which they play such an epistemic role. For example, Pryor writes in a footnote that our experiences give us the immediate justification they do because of the "phenomenal force" or way our experiences have of presenting propositions to us. He says that it "is difficult to explain what this "phenomenal force' amounts to, but I think that it is an important notion, and that it needs to be part of the story about why our experiences give us the justification they

\footnotetext{
Footnote 17 (continued)

(e.g., due to the presence of an omnipresent jokester) that the representational attitudes we'd have at such a world would be something other than beliefs, as opposed to simply, false beliefs. Likewise, there seems nothing amiss about supposing that (at such a world) our perception would be unreliable en masse, as opposed to, simply possessing something different in kind to perception.

18 Or, to take a well-worn example, consider human reproduction. For humans to continue to reproduce, sperm need to impregnate eggs often enough for the human race to survive. But that doesn't mean that sperm need to reliably impregnate eggs. Indeed, the vast majority of sperm fail to do so. Now, it might be objected that our perceptual faculties are not like human reproduction. We (following Graham) agree. But the point is that there is nothing inconceivable about perceptual faculties that are, in this respect, like human reproduction.

${ }^{19}$ For concern here, we'd need cause to suppose that the Davidsonian threshold would be higher than the Quinean threshold, which we address. Though we see no obvious reason it would be.
} 
do" (2000, 547, fn. 37). While this is admittedly vague, and more needs to be said about what phenomenal force amounts to, it could be taken to motivate a re-formulation of the dogmatist's thesis:

DOGMATISM*: Due to their phenomenal force, our experiences give us immediate and prima facie justification for believing their contents.

Might this more explicit formulation be reconcilable with UNIVERSALITY? It is hard to see how. Possibly, the phenomenal force (no matter how we choose to define it) of the experiences of our hypothesised creatures is different from the phenomenal force of our own experiences. In that case, DOGMATISM* is now explicitly about $u s$, in particular the phenomenal force of our experiences. So it is clearly not a universal principle.

We conclude that accepting DOGMATISM requires rejecting UNIVERSALITY. DOGMATISM is not a universally true epistemic principle, and this is so even if DOGMATISM is best understood against the backdrop of OBJECTIVITY, GENERALISM, ENTAILMENT and KNOWABILITY.

\subsection{Conservativism and Universality}

Now let us assume, again ex hypothesi, that CONSERVATIVISM is correct. UNIVERSALITY implies that, if CONSERVATIVISM is true for us, then it is also true for individuals who find themselves in very different, perhaps extremely different, circumstances than we do; their experiences, no less than ours do, give them prima facie justification for believing their contents because they are also entitled to accept that there is an external world with which they are causally interacting and that this world is mostly correctly revealed through their sense experience. We are going to argue that this is also implausible.

CONSERVATIVISM incorporates two claims. The first claim is about the conditions in which experiences give one prima facie justification for believing their contents. The conditions are: (i) that one has an entitlement to accept that there is an external world with which one is causally interacting; and (ii) that one has an entitlement to accept that the external world is mostly correctly revealed to one through sense experience. The second claim says that we meet these conditions because we do in fact have such entitlements, which are for us unearned and which require no background evidence, knowledge or the like. As Wright puts it, if one has an entitlement to some proposition $p$, then $p$ is "beyond rational reproach even though I can point to no cognitive accomplishment in my life, whether empirical or a priori, inferential or non-inferential, whose upshot could reasonably be contended to be that I had come to know that $\mathrm{P}$, or had succeeded in getting evidence justifying $\mathrm{P}$ " $(2004,174-75)$.

Compare now the conservativist's claim that we have an entitlement to (ii)—viz., that the external world is mostly correctly revealed to us through sense experiencewith the dogmatist's claim that our experiences give us immediate and prima facie justification for believing their contents. As we noted in Sect. 3.2, the dogmatist's claim is plausible only for subjects for whom the external world is generally correctly revealed to them through sense experience. Likewise, the conservativist's claim that we are 
entitled to accept that the external world is mostly correctly revealed to us though sense experience seems plausible only for subjects for whom the world is generally mostly correctly revealed through sense experience. Take our creatures, for whom the world is not generally mostly correctly revealed through sense experience. Just as it is not clear why the experiences of such creatures, in such a radically different world, should afford them with immediate prima facie justification to believe their contents (this was the argument from Sect. 3.2), it is likewise not clear why they should have unearned entitlements to accept that they are in worlds that mostly correctly reveal themselves.

Of course, the conservativist might point out that the anti-sceptical element of the position-viz., the positive claim that we have the entitlements we do-holds in our world precisely because of our world's features in conjunction with what counts as normal cognitive make up in this world. However, compare this point with the dogmatist's rejoinder: dogmatism is meant to apply in our world, not necessarily others. Such a rejoinder, in the case of dogmatism, is tantamount to giving up UNIVERSALITY. To say that dogmatism only applies in our world, or more weakly, only for creatures with similar cognitive features embedded in worlds with similar features, is to say that it is not universally valid. And so it is for the conservativist. CONSERVATIVISM, replete with the proviso that entitlements are entirely unearned and presuppose no kind of cognitive accomplishment, is not universally valid (e.g. valid in worlds very different to our own, inhabit by creatures very different to us) Thus, for much the same reasons, we conclude that, if UNIVERSALITY is true, CONSERVATIVISM is false.

We have argued that, if UNIVERSALITY is true, then both DOGMATISM and CONSERVATIVISM are false. Now, recall our aim here is to "stand back" from a sample first-order epistemological debate, and examine whether it is best seen as involving a commitment to B-absolutism, and, in particular, to UNIVERSALITY. If we are right that UNIVERSALITY makes trouble for both DOGMATISM and CONSERVATIVISM, then we take this to be good reason for thinking that neither the dogmatist nor the conservativist should be seen as committed to UNIVERSALITY. UNIVERSALITY is a metaepistemological thesis that would make trouble for both the dogmatist and the conservativist alike. So they are best off abandoning it. We can express this line of argument as a reductio against Boghossian's characterisation of the metaepistemological landscape as follows:

\section{Reductio}

1. B-absolutism is the only viable metaepistemological alternative to relativism [assumption, for reductio]

2. Proponents of dogmatism and conservativism are not B-relativists [premise] ${ }^{20}$

3. So, proponents of dogmatism and conservativism are B-absolutists [from 1 and 2].

4. B-absolutism involves a commitment to UNIVERSALITY [from B-absolutism]

5. So, proponents of dogmatism and conservativism are committed to UNIVERSALITY [from 3 and 4].

6. If UNIVERSALITY implies that dogmatism and conservativism are both false, then dogmatism and conservativism are not committed to UNIVERSALITY [premise]

${ }^{20}$ This premise is one we have not argued for explicitly, but which we take to be uncontroversial. 
7. UNIVERSALITY implies that dogmatism and conservativism are both false [Premise]

8. Therefore, dogmatism and conservativism are not committed to B-absolutism (contradiction).

A point to be gleaned from the foregoing reductio is that there are some "live options" (other than B-relativism) in epistemology-in particular, in the epistemology of perception - that are not best seen as committed to UNIVERSALITY. ${ }^{21}$ We can conclude then that neither DOGMATISM nor CONSERVATIVISM should be seen as applying universally. Whether they are valid for a given epistemic subject depends on the global environment the subject is in. As we will put it, they should be seen as environment-relative epistemic principles ("E-relativism"). They hold for some agents at some times, but not for other agents at other times, despite retaining other kinds of statuses traditionally associated with the absolutist package, and not with the B-relativist package.

In the final section we will say a little bit more about this E-relativist position that we think is ignored in Boghossian's characterisation of metaepistemology. But before turning to these broader issues, we want to consider two potential lines of retreat for Boghossian's universalist absolutist. Because we think both lines run into the same problem, we will explain both, before turning to the common problem.

The first line would be to defend DOGMATISM and CONSERVATIVISM as universal claims by adding qualifications or ceteris paribus clauses to them (and thus, to avoid the reductio argument by rejecting Premise (7)). For instance, Dogmatism could say that it's universally true that, ceteris paribus, our experiences give us immediate and prima facie justification for believing their contents, and CONSERVATIVISM could say that it's universally true that, ceteris paribus, our experiences give us prima facie justification for believing their contents because we are entitled in accepting that there is an external world with which one is causally interacting and that this world is mostly correctly revealed through sense experience. But, one could insist, all things simply aren't equal in worlds that don't correctly reveal themselves, like those inhabited by the creatures that are subject to constant illusions. ${ }^{22}$

The second line would be to argue that both DOGMATISM and CONSERVATIVISM can be seen as lower-order principles that are derivable from higher-order principles that can plausibly be seen as universal in Boghossian's sense. The thought would be that any reasons we have for thinking a particular epistemic principle is not universal are

\footnotetext{
${ }^{21}$ Of course, if the reader does not regard either dogmatism or conservativism as live or reasonable options, then the reader will naturally be sceptical of the ramifications the metaepistemological presuppositions of this example debate has for whether Boghossian has artificially restricted the space of live reasonable metaepistemological positions. However, that said, given the prominence of this debate in the epistemology of perceptual warrant, we submit that dogmatism and conservativism represent reasonable options, reasonable enough to warrant thinking that the debate, taken as a case study, could have implications we'd not be able to dismiss in the way we might if we were considering (say) positions that are entirely off the table.

${ }^{22}$ An initial problem with the first line is that it seems to rely on an ad hoc reading of the ceteris paribus clause, which takes for granted that all things are not equal in worlds that don't mostly correctly reveal themselves, a reading that arbitrarily regards the way the world reveals itself in the actual world as normal. But we'll set this to one side.
} 
really just reasons for thinking that the relevant principle must be a "local" version of some more general—and universal—epistemic principle. ${ }^{23}$

The problem with both these lines is that they lead to problems with two other components of the absolutist package: GENERALISM and ENTAILMENT. These principles say that we can explain particular epistemic judgements ("Catriona's belief is justified") by seeing them as entailed by general epistemic principles that (if we assume UNIVERSALITY) are universally true. On the first line, the problem is that DOGMATISM and CONSERVATIVISM are supposed to entail particular epistemic judgements, but if the versions of DOGMATISM and CONSERVATIVISM that are universally true include ceteris paribus clauses, then it is unclear how they can entail the truth or falsity of particular epistemic judgements. Absent a specification of whether all else is equal, the principles so construed won't entail any particular epistemic judgements.

On the second line, the problem is that DOGMATISM and CONSERVATIVISM are to be seen as derivable from some more general epistemic principle, and this more general principle it supposed to entail particular epistemic judgements. But what would this principle be? On the one hand, it is hard to see what sort of principle could underlie both views. Recall the principle Boghossian calls "observation":

OBSERVATION: For any observational proposition $\mathrm{p}$, if it visually seems to $\mathrm{S}$ that $\mathrm{p}$ and circumstantial conditions $\mathrm{D}$ obtain, then $\mathrm{S}$ is prima facie justified in believing p (Boghossian 2006a, 86).

But this principle doesn't entail both DOGMATISM and CONSERVATIVISM: dogmatists deny that any circumstantial conditions must obtain for our perceptual experiences to furnish us with prima facie justification for their contents.

On the other hand, even if a suitable principle could be found, it is no easier to see how it could entail particular epistemic judgements than it was to see how a principle that builds in ceteris paribus clauses could entail particular epistemic judgements. A suitable principle would have to be very abstract. It would, in effect, have to say no more than that we sometimes have prima facie justification for our perceptual beliefs. To say anything more-that we have such justification when certain conditions are met—would beg the question against the dogmatist. ${ }^{24}$

\footnotetext{
23 Thanks to an anonymous referee for urging us to consider this line.

24 As we've noted, attention to a sample first-order debate, viz., the perceptual warrant debate, suffices for the purposes of our dialectical objective here. That said, we do not take this particular debate to be unique in so far as it is an example of a first-order debate where the falsity of two rival positions is implied by a component (UNIVERSALITY) of what Boghossian takes to be the central alternative to B-Relativism. Although we lack the space to pursue this point here, it is worth considering that an analogous situation seems prima facie plausible with respect to the debate concerning the entitlement principle in the epistemology of testimony, which says (roughly) that speakers have an a priori entitlement to trust testimony (see Burge 1993; Graham 2010). Defenders of the entitlement principle clearly reject B-relativism, though they also reject (or, perhaps better, should reject) some of the core tenets of B-absolutism (i.e., UNIVERSALITY) given the implausibility of the conjunction of UNIVERSALITY and (most formulations of) entitlement principles.
} 


\section{E-Relativism: A Wider Context}

We will finish by putting the environment (or "E-") relativist view sketched above into its wider context. The basic idea is that epistemic principles, like DOGMATISM and CONSERVATISM, are principles that apply to particular groups of agents at particular times, not universally valid principles. But, while neither DOGMATISM nor CONSERVATIVISM can be defended against the background of Boghossian's full absolutist package, they don't cause problems for all of the parts of the package. In fact, they are clearly compatible with OBJECTIVITY, GENERALISM, ENTAILMENT and KNOWABILITY. That is, for all we have said, principles like DOGMATISM are objectively true, ground particular epistemic evaluations via entailment, and are knowable. But, for the reasons we have given, there is no reason to think that they are members of a uniquely correct set of epistemic principles that hold for all (rational) agents at all times. We want to finish by sketching a view on which epistemic principles, like DOGMATISM and CONSERVATIVISM, are explicitly environment relative despite being 'absolutist' in other respects. $^{25}$

There are two ways to implement environment relativity, both of which involve denying UNIVERSALITY. We will outline each way, then explain which we favour. The first way builds the environment relativity into the principle itself. For instance, DOGMATISM would look like this:

DOGMATISM-RELATIVISED: The experiences of individuals who inhabit global environments like ours and are cognitively like us give them immediate and prima facie justification for believing the contents of those experiences.

This principle isn't universally valid in the sense that it is explicitly restricted to particular individuals at particular times. (That is, individuals who inhabit a global environment that is like our present global environment, and who are cognitively like us). There will be other principles that talk about the experiences of individuals who inhabit global environments very different to our own. For instance:

ANTI-DOGMATISM-RELATIVISED: The experiences of individuals who inhabit global environments very different to ours and/or are not cognitively like us may not give them immediate and prima facie justification for believing the contents of those experiences.

One might think that these principles are members of the uniquely correct set of epistemic principles because, while DOGMATISM-RELATIVISED and ANTI-DOGMATISM-RELATIVISED are about different individuals, they can both be true. That is, they aren't inconsistent. While one could stretch UNIVERSALITY in such a way that there is a uniquely correct set of epistemic principles so long as the various epistemic principles concerning different individuals are consistent, this doesn't strike us as a particularly interesting way to interpret UnIVERSALITY. Compare the view that moral principles are explicitly about the moral responsibilities of

\footnotetext{
${ }^{25}$ For the sake of simplicity, in what follows we just talk about DOGMATISM. But everything we say will go for CONSERVATIVISM too.
} 
individuals like us who inhabit an environment like ours, and there may be other, very different, moral principles governing the behaviour of individuals with different psychologies or who inhabit a different sort of environment. This looks like a paradigm of a non-universalist moral view on which there are a plurality of different moralities. For instance, one could use this sort of non-universalist thinking to argue that there are different moralities for different types of individual (a morality for individuals with empathy, a morality for individuals lacking empathy, etc.), or different moralities for different cultures (see e.g. Harman 1975). Or one could use it to argue that there are different moralities for different times (a Greek morality, a mediaeval morality, etc.) (see e.g. Williams 1974)

The second way doesn't put the environment relativity into the principle itself, but holds that the principles themselves are true or false relative to environments. So, for instance, DOGMATISM is true relative to our global environment, but false relative to the global environment of the creatures who inhabit a world of illusions. According to this view, the truth of the principles themselves is an environment relative matter. Because the truth of the principles themselves is environment relative, the principles can't be universally true (truth is relative), or uniquely correct (relative to different environments, one is true, the other false).

While more could be said about the details of the second view, we think this is enough to see why the first view is preferable. The second view has the consequence that particular epistemic judgements, like the judgement that John's immediate perceptual belief that there is a red cup on the table in front of him is prima facie justified, are true relative to our global environment, but may be false relative to other environments. This immediately poses a problem: if the judgement is true relative to our environment yet false relative to another environment, then is the belief justified or not? The answer seems to be that it depends who you are. If you are an inhabitant of our environment, it is. If you are an inhabitant of some other environment, it might not be. But it is (to say the least) unorthodox to think of justification in this way. Accordingly, we prefer the first way of developing environment relativism.

\section{Conclusion}

Epistemic principles state the conditions under which beliefs have the status of being justified. One key question in metaepistemology concerns the nature of these principles: are they objectively true? Is there a unique set of them? Are they binding on all epistemic agents? What relationship do they stand into particular epistemic judgements? In his work Boghossian proposes a form of metaepistemological absolutism we called "B-absolutism". The B-absolutist's opponent is someone who rejects all (or almost) all the tenets of B-absolutism. In this paper we have argued that this stark opposition between B-absolutism and "B-relativism" is a mischaracterisation of the metaepistemological landscape. There is clearly room for views that deny some of the tenets of B-absolutism without aligning with B-relativism by denying all. We have made our case by looking at an illustrative case study: the debate 
between dogmatists and conservativists in the epistemology of perception. We have argued that these views are not best seen as committed to UNIVERSALITY. That is, they are not best seen as being committed to epistemic principles that bind all epistemic agents. Rather, they are best seen as committed to principles that bind some epistemic agents but not others. This leads to a "third option" (or "way") in metaepistemological theorising, a weaker form of absolutism we call "E-relativism".

What relevance can metaepistemology have to first-order epistemology? We think it can impart a certain modesty to it. Epistemology is not in the business of articulating epistemic principles that govern all possible epistemic agents, situated in all conceivable physical and social environments. It is in the business of articulating principles relevant to us, as we are in fact constituted and situated, and in light of our actual epistemic practices.

Acknowledgements We are grateful to Martin Kusch for helpful feedback on a previous version of this paper, along with three anonymous referees and the editors at Erkenntnis. McKenna's research on this paper was assisted by funding from the ERC Advanced Grant Project "The Emergence of Relativism" (Grant No. 339382).

Open Access This article is distributed under the terms of the Creative Commons Attribution 4.0 International License (http://creativecommons.org/licenses/by/4.0/), which permits unrestricted use, distribution, and reproduction in any medium, provided you give appropriate credit to the original author(s) and the source, provide a link to the Creative Commons license, and indicate if changes were made.

\section{References}

Alston, W. P. (1988). The deontological conception of epistemic justification. Philosophical Perspectives, 2, 257-299.

Boghossian, P. (2001). How are objective epistemic reasons possible? Philosophical Studies, 106(12), $1-40$.

Boghossian, P. (2006a). Fear of knowledge: Against relativism and constructivism. Oxford: Oxford University Press.

Boghossian, P. (2006b). What is relativism. In P. Greenough \& M. P. Lynch (Eds.), Truth and realism (pp. 13-37). New York: Oxford University Press.

Boghossian, P. (2007). The case against epistemic relativism: Replies to Rosen and Neta. Episteme, $4(1), 49-65$.

Boghossian, P. (2008). Replies to Wright, MacFarlane and Sosa. Philosophical Studies, 141(3), 409-432.

Burge, T. (1993). Content preservation. Philosophical Review, 102(4), 457-488.

Carter, J. Adam. (2016). Metaepistemology and relativism. Cham: Palgrave Macmillan.

Chrisman, M. (2007). From epistemic contextualism to epistemic expressivism. Philosophical Studies, 135(2), 225-254.

Coliva, A. (2012). Varieties of failure (of warrant transmission: what else?!). Synthese, 189(2), 235-254.

Correia, F., \& Schnieder, B. (2012). Grounding: An opinionated introduction. In F. Correia \& B. Schnieder (Eds.), Metaphysical grounding: Understanding the structure of reality (pp. 1-36). Cambridge: Cambridge University Press.

Cuneo, T. (2007). The normative web: An argument for moral realism. Oxford: Oxford University Press.

Dancy, J. (2004). Ethics without principles. Oxford: Oxford University Press.

Davidson, D. (1986). A coherence theory of truth and knowledge. In E. LePore (Ed.), Truth and interpretation. Perspectives on the philosophy of Donald Davidson (pp. 307-319). Hoboken: Blackwell. 
Davies, M. (2000). Externalism, architecturalism, and epistemic warrant. In C. Wright, B. Smith, \& C. Macdonald (Eds.), Knowing our own minds (pp. 321-363). Oxford: Oxford University Press.

Field, H. (2009). Epistemology without metaphysics. Philosophical Studies, 143(2), 249-290.

Fine, K. (2012). Guide to ground. In F. Correia \& B. Schnieder (Eds.), Metaphysical grounding: Understanding the structure of reality (pp. 37-80). Cambridge: Cambridge University Press.

Gibbard, A. (1990). Wise choices, apt feelings: A theory of normative judgment. Cambridge: Harvard University Press.

Ginet, C. (1975). Knowledge, perception, and memory. Dordrecht: D. Reidel.

Graham, P. J. (2010). Testimonial entitlement and the function of comprehension. In D. Pritchard, A. Millar, \& A. Haddock (Eds.), Social epistemology (pp. 148-174). Oxford: Oxford University Press.

Graham, P. J. (2012). Epistemic entitlement. Nô̂s, 46(3), 449-482.

Harman, G. (1975). Moral relativism defended. Philosophical Review, 84(1), 3-22.

Huemer, M. (2007). Compassionate phenomenal conservatism. Philosophy and Phenomenological Research, 74(1), 30-55.

Kusch, M. (2010). Epistemic replacement relativism defended. In M. Suarez (Ed.), EPSA epistemology and methodology of science: Launch of the European Philosophy of Science Association (pp. 165-175). Berlin: Springer.

Lyons, J. (2009). Perception and basic beliefs: Zombies, modules, and the problem of the external world. Oxford: Oxford University Press.

MacFarlane, J. (2008). Boghossian, bellarmine, and bayes. Philosophical Studies, 141(3), 391-398.

MacFarlane, J. (2014). Assessment sensitivity: relative truth and its applications. Oxford: Oxford University Press.

McDowell, J. (1994). Mind and world. Cambridge, MA: Harvard University Press.

Neta, R. (2007). In defense of epistemic relativism. Episteme, 4(1), 30-48.

Olson, J. (2011). Error theory and reasons for belief. In A. Reisner \& A. Steglich-Petersen (Eds.), Reasons for belief (pp. 75-93). Cambridge: Cambridge University Press.

Palmer, S. (1999). Vision science: From photons to phenomenology. Cambridge, MA: MIT Press.

Pollock, J. L. (1986). Contemporary theories of knowledge. Reno: Hutchinson.

Pritchard, D. (2012). Epistemological disjunctivism. Oxford: Oxford University Press.

Pryor, J. (2000). The Skeptic and the Dogmatist. Noûs, 34(4), 517-549.

Pryor, J. (2004). What's wrong with Moore's argument? Philosophical Issues, 14(1), 349-378.

Quine, W. V. O. (Ed.). (1969). Epistemology naturalized. In Ontological relativity and other essays (pp. 69-90). New York: Columbia University Press.

Rosen, G. (2007). The case against epistemic relativism: Reflections on chapter 6 of fear of knowledge. Episteme, 4(1), 10-29.

Sider, T. (2015). Nothing over and above. Grazer Philosophische Studien, 91, 191-216.

Siegel, S. (2010). The contents of visual experience. New York: Oxford University Press.

Sosa, E. (2008). Boghossian's fear of knowledge. Philosophical Studies, 141(3), 399-407.

Stalnaker, R. (1974). Pragmatic presuppositions. In R. Stalnaker (Ed.), Context and content (pp. 47-62). Oxford: Oxford University Press.

Stich, S. (1991). The fragmentation of reason: Preface to a pragmatic theory of cognitive evaluation. Harvard, MA: MIT Press.

Streumer, B. (2013). Can we believe the error theory? Journal of Philosophy, 110(4), 194-212.

Sudduth, M. (2008). Defeaters in epistemology. In J. Fieser \& B. Dowden (Eds.), Internet encyclopedia of philosophy. http://www.iep.utm.edu/ep-defea/.

Williams, B. (1974). The truth in relativism. Proceedings of the Aristotelian Society, 75, 215-228.

Wright, C. (2004). Warrant for nothing (and foundations for free)? Aristotelian Society Supplementary, 78(1), 167-212.

Wright, C. (2007). The Perils of dogmatism. In S. Nuccetelli \& G. Seay (Eds.), Themes from G. E. Moore: New essays in epistemology (pp. 25-48). Oxford: Oxford University Press.

Wright, C. (2008). Fear of relativism? Philosophical Studies, 141(3), 379-390.

Publisher's Note Springer Nature remains neutral with regard to jurisdictional claims in published maps and institutional affiliations. 